АРСЛАНОВ Ш.Д., АКИЛИН И.В., АРСЛАНОВ Д.Э.

АКИЛИН ИВАН ВЛАДИСЛАВОВИЧ

магистрант кафедры «Менеджмент» ФБГБОУ ВО «Дагестанский государственный технический университет», e-mail: ivango05@yandex.ru

АРСААНОВ ДЖАВАД ЭМИРОВИЧ

к.э.н., дочент кафедры «ФОизика» ФБГБОУ ВО «Дагестанский государственный технический университет», e-mail: ars_dgu@mail.ru

\title{
СОВРЕМЕННЫЕ ПРОБАЕМЫ РАЗВИТИЯ БАНКОВСКОЙ СФЕРЫ РЕГИОНА
}

Аннотауия. Актуальность изучения банковской сферы региона определяется тем, что данная структура соииально-экономической системы является важным механизмом саморазвития и стабилизащии всего региона в целом. Банковская сфера региона, обеспечивая перераспределение денежных средств, кредитование и расчеты, способствует росту производительности общественного труда. Џель исследования - изучение влияния банковской сферы региона на развитие, полноту, доступность и охват банковских услуг, предоставляемых физическим и юридическим лицам. Задачи исследования: 1) выявить роль и место банковской сферы региона в экономической системе страны; 2) изучить степень доступности и полноту охвата предоставляемых банковских услуг; 3) определить эффективность банковской сферы региона. Метод и методология проведения работы. Исследование основывается на общенаучной методологии, которая предусматривает применение системного подхода к решению проблем. Основой данной работы являются эмпирические наблюдения авторов за фактическим состоянием регионального банковского сектора, подкрепленные аналитическими выводами доступных данных. Резудьтаты. Определены тендениии формирования и развития региональных банков и банковской сферы региона. Выявлены современные проблемы развития банковской сферы региона. Доказано, что дисбаланс в территориальном размещении банков приводит к возникновению определенных трудностей при формировании регионального кредитнофинансового рынка. Полученные результаты могут быть использованы органами государственной власти при формировании стратегии активизащии работы регионального банковского сектора, увеличения объема кредитования реального сектора региона, а также при формировании наиболее оптимального механизма обращения финансовокредитного ресурса. Выводы. Сложившаяся ситуация является показателем необходимости снижения диспропориии, возникшей в ходе спеиифики развития регионов, посредством выравнивания их сочиально-экономического развития, что также позволит достигнуть повышения уровня благосостояния всего населения. В частности, необходимо достигнуть конкретных результатов в следующих направлениях развития банковского сектора: 1) определить систему, позволяющую снижать уровень собственного капитала банков, осуществляющих свою деятельность на территории определенного региона; 2) определить возможность снижения рисков по кредитованию (в частности, долгосрочному); 3 ) предусмотреть возможность создания условий для аккумулирования и инвестирования привлеченного капитала на развитие как сочиально-экономической системы региона, так и региональных финансово-кредитных учреждений; 4) определить стратегию развития региональной банковской системы, направленную на развитие финансовокредитной системы региона.

Ключевые слова: регион, банковская система, региональный банк, потенциал, развитие 
ARSLANOV SHAMIL JAVADOVICH

Candidate of Economic Sciences, Senior Research Associate of FSBIS "Institute of Social-Economic Studies of DSC of the RAS", e-mail: ars_dgu@mail.ru

AKILIN IVAN VLADISLAVOVICH

Master's Degree Student of the Department of "Management" of FSBEI of HE

"Dagestan State Technical University", e-mail: ivango05@yandex.ru

ARSLANOV JAVAD EMIROVICH Candidate of Economic Sciences, Associate Professor of the Department of "Physics" of FSBEI of HE "Dagestan State Technical University", e-mail: ars_dgu@mail.ru

\section{MODERN PROBLEMS OF DEVELOPMENT OF THE BANKING INDUSTRY OF THE REGION}

Abstract. The relevance of studying the banking industry of the region is determined by the fact that this structure of the social-economic system is an important mechanism of selfdevelopment and stabilization of the whole region on overall. The banking industry of the region through redistribution of monetary funds, crediting and calculations stipulates growth of productivity of social labor. The goal of the study is researching the impact of the banking industry of the region on the development, completeness, availability and spread of banking services provided for entrepreneurs and companies. The goals of the study are the following: 1) find the role and place of the banking industry of the region in the economic system of the country; 2) study the degree of availability and completeness of spread of the banking services provided; 3 ) determine the effectiveness of the banking industry of the region. The method and methodology of completing the study. The study is based on the general scientific methodology that stipulates using a systemic approach to solving problems. The foundation of this study are empirical observations of the authors over the actual state of the regional banking sector supported by analytical conclusions of the available data. The results. We have determined the tendencies of the formation and development of regional banks and the banking industry of the region. We have found the modern problems of development of the banking industry of the region. It has been proven that an imbalance in the territorial placement of banks leads to the formation of certain difficulties when forming a regional credit-financial market. The results obtained may be used by the governmental authorities when forming a strategy of activation of work of the regional banking sector, increasing the volume of crediting of the real sector of the region, as well as when forming the most optimal mechanism of turnover of the financial-credit resource. The conclusions. The situation that formed is an indicator of the need to reduce the disproportion that arose in the course of the specific development of regions through evening out their social-economic development which will also allow to achieve improvement of the level of welfare of the whole population. In particular, it is necessary to achieve specific results in the following areas of development of the banking sector: 1) determine a system allowing to reduce the level of the equity capital of banks working on a territory of a certain region; 2) determine the possibility of reducing the risks of crediting (in particular, for long-term crediting); 3) stipulate a possibility of creating conditions to accumulate and invest the attracted capital for development of both the social-economic system of the region, and the regional financial-credit institutions; 4) determine a strategy of development of the regional banking system directed towards the development of a financial-credit system of the region. Keywords: a region, a banking system, a regional bank, a potential, development

Введение. Формирование и развитие современного и высокотехнологичного регионального банковского сектора является на сегодняшний день определяющим вектором развития как региональной социально-экономической системы, так и всей банковской системы страны.

В современных условиях финансовой неопределенности и нестабильности все большее 
значение приобретает стабильная и устойчивая система региональных кредитно-финансовых учреждений, основной задачей которой должно стать обеспечение всех финансово-кредитных потребностей регионального сегмента экономики и, в первую очередь, создание системы бесперебойного долгосрочного кредитования реального сектора региона.

Несомненно, актуальность развития банковской сферы региона определяется тем, что данная структура социально-экономической системы является важным механизмом саморазвития и стабилизации всего региона в целом. Банковская сфера региона, обеспечивая перераспределение денежных средств, кредитование и расчеты, способствует росту производительности общественного труда.

В условиях финансовой нестабильности задача создания полноценной и эффективной банковской системы (банки и банковская инфраструктура) становится одной из приоритетных задач реформирования экономической системы РФ [1].

Актуальность исследования определяет и его цель - изучение влияния банковской сферы региона на развитие, полноту, доступность и охват банковских услуг, предоставляемых физическим и юридическим лицам.

Цель нашего исследования может быть достигнута только при решении следующих задач:

1) выявить роль и место банковской сферы региона в экономической системе страны;

2) изучить степень доступности и полноту охвата предоставляемых банковских услуг;

3) определить эффективность банковской сферы региона.

Методы исследования. Изучение региональной банковской сферы как направление появилось относительно недавно. Современная экономическая мысль, анализируя региональную банковскую систему, особое внимание уделяет управлению ими.

В дореформенный период в условиях господства плановой экономики банковский сектор представлял собой четко структурированную и иерархическую систему, управляемую из единого центра $[2,3]$.

Уход от планового уклада экономики привел к формированию нового государственного уклада - федеративного государства, что привело к формированию отдельных федеративных субъектов со своей спецификой. Специфика развития регионов отразилась и на формировании региональных банковских сфер, развитие которых имело неравномерный и несбалансированный характер. это объясняется резким ростом числа частных банков и кредитно-финансовых учреждений в экономически более развитых регионах страны. Диспропорция региональных банковских систем актуальна и на сегодняшний день, поскольку остается малоизученным экономическим направлением.

Современный анализ экономической мысли позволяет нам заключить, что мы не имеем четко определенного понятия «региональный банк», однако есть мнение, что под региональным банком необходимо понимать банк, который территориально располагается и осуществляет свою деятельность на определенной ограниченной территории (в регионе).

Рассматривая банковскую систему, необходимо отметить, что именно банковская система является необходимой структурной единицей современной рыночной экономики. Современная банковская сфера характеризуется способностью организации и управления общегосударственной как платежной, так и расчетной систем, а также инвестированием в экономику аккумулированных средств вкладчиков.

Параметры функционирования банковской системы проявляют влияние на все общество, являясь предметом государственного регулирования. Одним из таких параметров является модернизация [4].

Современная экономическая теория рассматривает модернизацию как определенный комплекс явлений и процессов глобализации, развития научно-технического процесса, развития информационного общества, повышение пространственной и общественной мобильности, ведущие к образованию современного общества в противовес классическому. В свою очередь, региональная модернизация должна основываться на максимально оптимальном взаимодействии всех возможных ресурсов, а также развитии эффективных механизмов аккумулирования всех видов экономического потенциала региона. Сам процесс модернизации должен основываться на структурной перестройке экономики - на перераспределении общего ресурсного потока между наиболее перспективными секторами, которые позволят добиться экономически 
значимых результатов.

Современный анализ сложившейся банковской системы и соответствующей инфраструктуры позволяет с определенной долей уверенности говорить о наличии перекосов в территориальном аспекте ее развития.

Так, к примеру, в 2016 г. количество банков составляло 733 единицы, а в 2015 г. - 834, то есть отчетливо прослеживается сокращение на 101 единицу (табл. 1 [5]).

Таблица 1

Количество действующих банков России по федеральным округам, 2010-2016 гг.

\begin{tabular}{|l|c|c|c|c|c|c|c|}
\hline \multicolumn{1}{|c|}{ Федеральные округа } & $\mathbf{2 0 1 0}$ & $\mathbf{2 0 1 1}$ & $\mathbf{2 0 1 2}$ & $\mathbf{2 0 1 3}$ & $\mathbf{2 0 1 4}$ & $\mathbf{2 0 1 5}$ & $\mathbf{2 0 1 6}$ \\
\hline Центральный & 598 & 585 & 572 & 564 & 547 & 504 & 434 \\
\hline Северо-Западный & 75 & 71 & 69 & 70 & 70 & 64 & 60 \\
\hline Южный & 113 & 47 & 45 & 46 & 46 & 43 & 37 \\
\hline Северо-Кавказский & - & 57 & 56 & 50 & 43 & 28 & 22 \\
\hline Приволжский & 125 & 118 & 111 & 106 & 102 & 92 & 85 \\
\hline Уральский & 54 & 51 & 45 & 44 & 42 & 35 & 32 \\
\hline Сибирский & 62 & 56 & 54 & 53 & 51 & 44 & 41 \\
\hline Дальневосточный & 31 & 27 & 26 & 23 & 22 & 22 & 17 \\
\hline Крымский & - & - & - & - & - & 2 & 5 \\
\hline По РФ & 1058 & 1012 & 978 & 956 & 923 & 834 & 733 \\
\hline
\end{tabular}

Анализ распределения банков по федеральным округам позволяет нам сделать вывод, что большинство банков сосредоточено в Европейской части РФ, а в Дальневосточном, Северном и Уральском Федеральных округах их значительно меньше, хотя они являются основными ресурсными центрами страны.

Такой дисбаланс в территориальном размещение банков приводит к возникновению определенных трудностей при формировании регионального кредитно-финансового рынка. Если обратиться к исследованию структуры активов финансово-кредитных организаций, то по факту можно говорить о несоответствии количества банков экономическому потенциалу регионов и о продолжающемся их сокращении (табл. 2 [5]).

Таблицуа 2

Активы кредитных организаций и их структура по месту регистрации по состоянию на 01.01.2014

\begin{tabular}{|l|c|c|}
\hline \multicolumn{1}{|c|}{ Федеральные округа } & Активы, млрд руб. & Удельный вес \\
\hline Всего & 57423,07 & 100,0 \\
\hline Центральный, в т. ч. & 51391,2 & 89,5 \\
\hline г. Москва & 50975,4 & 88,8 \\
\hline Северо-Западный, в т. ч. & 1650,4 & 2,9 \\
\hline Санкт-Петербург & 1487,1 & 2,6 \\
\hline Южный & 303,2 & 0,5 \\
\hline Северо-Кавказский & 57,3 & 0,1 \\
\hline Приволжский & 1562,2 & 2,7 \\
\hline Уральский & 1275,2 & 2,2 \\
\hline Сибирский & 623,8 & 1,1 \\
\hline Дальневосточный & 559,8 & 1,0 \\
\hline
\end{tabular}


АРСЛАНОВ Ш.Д., АКИЛИН И.В., АРСЛАНОВ Д.Э.

СОВРЕМЕННЫЕ ПРОБЛЕМЫ РАЗВИТИЯ БАНКОВСКОЙ СФЕРЫ РЕГИОНА

На сегодняшний день вся банковская сфера и практически все банковские активы сосредоточены в Москве и Санкт-Петербурге, в то время как остальная часть РФ обслуживается банками, активы которых составляют менее $10 \%$ [6,7].

К примеру, только в Приволжском федеральном округе формируется от 15 до 19\% валовой добавленной стоимости, а кредитно-финансовые учреждения региона обладают менее $3 \%$ активов $[8,9,10]$.

Однако имеет место и другая тенденция. Так, при росте валового регионального продукта идет снижение числа региональных банков, однако при этом возрастает их капитализация, формируется развитая инфраструктура, позволяющая банковскому сектору включаться в социальную жизнь региона.

Современная региональная банковская система должна являться неотьемлемой частью общей национальной банковской системы и выступать в роли ее представительства на местах. Учитывая масштабы РФ и территориально-географическую разобщенность финансовоэкономических центров, необходимо помнить, что национальная экономика отличается рядом специфических черт, которые и предопределили развитие диспропорций в банковской сфере. Развитие экономики России сегодня невозможно без работы над преодолением сложившийся диспропорции в банковской сфере.

Сложившийся объективный характер формирования и развития региональных банковских систем опирается на конкретные положения теории пространства, которая предусматривает определенные условия, наличие которых предусматривает возникновение региональных банковских систем: $[11,12,13]$

- наличие территориального аспекта в формировании прибавочного продукта и общей совокупного государственного общественного продукта;

- диспропорция в дислокации производительных сил и, как следствие, диспропорция в формирования национального общественного продукта;

- целесообразность перераспребделения национального общественного продукта в рамках его территориального выравнивания;

- объективно существующая необходимость в концентрации финансов для реализации общественных потребностей на территории всего государства и решения внутрирегиональных приоритетных задач;

- финансово-кредитные учреждения и коммерческие банки, как национальные, так и иностранные, головные офисы которых располагаются на территории определенного региона, а также наличие сети филиалов, реализующих свою деятельность на этой территории.

Согласно теории пространства, становление региональных банковских систем определяется следующими факторами:

- становление ресурсной базы финансово-кредитных учреждений и банков складывается по территориальному признаку;

- присущей банкам и финансово-кредитным учреждениям строго иерархической системы управления с выделенным территориальным звеном;

- объективной взаимосвязью финансово-кредитных учреждений и банков практически со всеми субъектами региональной социально-экономической системы.

Учитывая все вышеизложенное, можно еще раз сформулировать определение термина «региональная банковская сфера» - определенная совокупность различных субъектов кредитно-финансового сектора региональной социально-экономической системы, действующих на основании законов РФ на территории конкретного региона.

Региональная банковская система характеризуется тем, что в состоянии оказывать влияние на развитие экономики региона, непосредственно используя на его территории накопленный кредитно-финансовый ресурс.

Подобное качество банковской системы региона обеспечивается при наличии следующих принципов:

1. Принцип адекватности. Система региональных банков должна полностью соответствовать существующим потребностям социально-экономической системы.

2. Принцип функциональности. Региональная банковская система на всех этапах своего развития должна функционировать в полном соответствии с объемом кредитно-финансовых 
потребностей.

Результаты. Установлено что в современной экономической литературе нет четко определенных понятий «региональный банк» и «региональная банковская система», однако существует мнение, что под региональным банком необходимо понимать банк, который территориально располагается и осуществляет свою деятельность на определенной ограниченной территории (регионе).

Определены исторически обусловленные тенденции формирования и развития региональных банков и банковской сферы региона, которые являются необходимой структурной единицей современной рыночной экономики и характеризуются способностью организации и управлением как платежной, так и расчетной систем.

Выявлены современные проблемы развития банковской сферы региона. Доказано, что дисбаланс в территориальном размещении банков приводит к возникновению определенных трудностей при формировании регионального кредитно-финансового рынка.

Выводы. Сложившаяся ситуация является показателем необходимости снижения диспропорции, возникшей в ходе специфики развития регионов, посредством выравнивания их социально-экономического развития, что также позволит достигнуть повышения уровня благосостояния всего населения.

В частности, на федеральном уровне необходимо:

1) определить систему, позволяющую снижать уровень собственного капитала банков, осуществляющих свою деятельность на территории определенного региона, с учетом наличия в них крупных корпоративных клиентов;

2) определить возможность снижения рисков по кредитованию (в частности, долгосрочному), поскольку денежные ресурсы клиентов банка чаще всего хранятся на депозитных счетах до востребования;

3) предусмотреть возможность создания условий для аккумулирования и инвестирования привлеченного капитала на развитие как социально-экономической системы региона, так и региональных финансово-кредитных учреждений;

4) определить стратегию развития региональной банковской системы, направленную на развитие финансово-кредитной системы региона с его тесной взаимосвязью с реальным сектором экономики.

Перечисленные меры позволят активизировать работу регионального банковского сектора, добиться увеличения объема кредитования реального сектора региона, а также позволят сформировать наиболее оптимальный механизм обращения финансово-кредитного ресурса.

Литература

1. Бровкина, Н. Е. Проблемы и перспективы регионального развития кредитного рынка // Экономика, налоги, право. 2015. № 6. С. 48-54.

2. Масленников, В. В., Масленников, С. В. Современные проблемы развития регионального сегмента банковской системы России // Экономика, налоги, право. 2015. № 6. С. 40-47.

3. Попова, А. Д., Езангина, И. А. Роль региональньхх банков в банковской системе России // Фундаментальные и прикладные исследования в современном мире. 2015. № 12-2. C.112-117.

4. Русина, А. Е. Роль региональных банковских систем в модернизаџии экономики // Актуальные проблемы современной науки. 2012. С.157-159.

5. Федеральная служба государственной статистики РФ [Электронный ресурс]. - URL : http:// www.gks.ru (Дата обращения: 10.06.2018).

6. Морозов, И. К. Анализ роли регионального сегмента банковской системы // Молодежный научный форум : Общественные и экономические науки : электр. сб. ст. по мат. XL междунар. студ. науч. практ. конф. № 11(40). - URL : https://nauchforum.ru/archive/MNF_social/11(40).pdf (дата обращения: 22.06.2018).

7. Арсланова, Х. Д. Современная региональная банковская система // Современные проблемы и перспективы развития банковского сектора России : материалы II всероссийской научно-практической конференции с международным участием (заочной). 2017. С. 63-67.

8. Арсланова, Х. Д., Шахтаманова, Л. Г. Анализ и оченка инвестиџионной политики регионов СКФО // Современные тренды российской экономики : вызовы времени - 2017 : материаль международной научно-практической конференции. 2017. С. 44-46.

9. Петросяни, В. З., Арсланова, Х. Д., Ниналалова, Л. Г Зарубежный опыт государственного регулирования регионального развития // Региональные проблемы преобразования экономики. 2016. № 10. С. 99 105.

10. Арсланов, Ш. Д., Идзиев, Г. И., Рабаданова, А. А., Арсланова, Х. Д. Социально-экономическая ситуаuчия Северо-Кавказского федерального округа // Проблемы и перспективы использования потенциала 
АРСЛАНОВ Ш.Д., АКИЛИН И.В., АРСЛАНОВ Д.Э.

СОВРЕМЕННЫЕ ПРОБЛЕМЫ РАЗВИТИЯ БАНКОВСКОЙ СФЕРЫ РЕГИОНА

возобновляемых источников энергии в регионе : материалы круглого стола ; под общ. ред. Дохоляна C.B. 2015. C. 109-115.

11. Levitt, T. Globalisation of Markets // Global Marketing Management : Cases and Readings ; ed. by R.D. Buzzel, Y.A. Quelch, C.A. Bartellet. - 3rd ed. - N.Y. : Addison-Wesley Publishing Company, 1995. P. 15.

12. Alchian, Armen A. Uncertainty, Evolution and Economic Theory // Journal of Political Economy. 1950. Vol. 58. P. 211-221.

13. Nelson, R. R., Winter, S. J. An evolutionary theory of economic change. - M. : Finstatinform, 2000.

\section{References:}

1. Brovkina, N. E. Problems and prospects of development of the regional credit market // Economy, taxes, law. 2015. No. 6. P. 48-54.

2. Maslennikov, $V . V$., Maslennikov, $S$. V. Modern problems of development of the regional segment of the banking system of Russia // Economy, taxes, law. 2015. No. 6. P. 40-47.

3. Popova, A. D., Sangina, I. A. the Role of regional banks in the Russian banking system // Fundamental and applied studies in the modern world. 2015. No. 12-2. P. 112-117.

4. Rusina, A. E. the Role of regional banking systems in the modernization of economy // Actual problems of modern science. 2012. P. 157-159.

5. Federal state statistics service of the Russian Federation [Electronic resource]. - URL : http://www.gks.ru (date accessed: 10.06.2018).

6. Morozov, I. K. analysis of the role of the regional segment of the banking system / / Youth scientific forum: Social and economic Sciences: electr. collection of articles on the Mat. XL international. stud. science.- practice. Conf. No. 11(40). - URL : https://nauchforum.ru/archive/MNF social/11(40).PDF (date accessed: 22.06.2018).

7. Arslanov, H. D. Modern regional banking system // Modern problems and prospects of development of Bank sector of Russia : materials of the second all-Russian scientific-practical conference with international participation (in absentia). 2017. P. 63-67.

8. Arslanov, H. D., Shakhtamirov, L. G. Analysis and evaluation of investment policy of the regions of the North Caucasus Federal district // Modern trends of the Russian economy : current challenges - 2017 : materials of international scientific-practical conference. 2017. P. 44-46.

9. Petrosyants V. Z., Arslanov, H. D., Minallah, L. G Foreign experience of state regulation of regional development // Regional problems of transformation of the economy. 2016. No. 10. P. 99-105.

10. Arslanov, S. D., Iziev, G. I., Rabadanov, A. A., Arslanov, Kh. d. the Socio-economic situation of the North Caucasus Federal district // Problems and prospects of using the potential of renewable energy in the region : materials of the round table; ed. by With Boholana.V. 2015. P. 109-115.

11. Levitt T. globalization of markets / / global marketing management: cases and readings; ed. Buzzel R. D., Quelch, A. J., S. A. Bartellet. - 3rd ed. - N. Y.: Addison-Wesley Publishing Company, 1995. P. 15.

12. Alchian, A. uncertainty, evolution and economic theory//journal of political economy. 1950. Thom. 58. C. 211-221.

13. Nelson R. R., winter, S. an evolutionary theory of economic change. - Moscow: Finstatinform, 2000. 